\title{
Trocas gasosas entre metano e óxido nitroso entre solo e atmosfera em diferentes tipos de cobertura na região oeste do Pará, Brasil
}

A mudança de uso e manejo do solo vem ocorrendo de forma dinâmica e intensa, sobretudo na região Amazônica, o que pode resultar em fonte ou dreno de gases do efeito estufa para a atmosfera. Este trabalho quantificou as trocas gasosas de metano $(\mathrm{CH} 4)$ e óxido nitroso (N2O) entre solo e atmosfera em diferentes tipos de cobertura, e analisou as variáveis ambientais reguladoras das trocas gasosas em diferentes microbacias da região Oeste do estado do Pará. As medidas foram realizadas através de câmaras instaladas no campo, posteriormente analisadas por cromatografia gasosa. Não houve diferença significativa no fluxo de metano mediante os efeitos da mudança no uso da terra em campos agrícolas de soja $(0,23 \mathrm{mg}-\mathrm{C} / \mathrm{m} 2 / \mathrm{h})$, pastagens $(0,31 \mathrm{mg}-\mathrm{C} / \mathrm{m} 2 / \mathrm{h})$ e capoeira $(0,42 \mathrm{mg}-\mathrm{C} / \mathrm{m} 2 / \mathrm{h})$. Encontrou-se diferença estatística entre o fluxo de óxido nitroso relacionado ao tipo de cobertura do solo, onde o fluxo de capoeira (19,57 mg-N/m2/h) foi menor que o da pastagem $(36,81 \mathrm{mg}-\mathrm{N} / \mathrm{m} 2 / \mathrm{h})$ e agricultura $(40,08 \mathrm{mg}-\mathrm{N} / \mathrm{m} 2 / \mathrm{h})$. Houve diferença entre os fluxos de metano encontrados na soja em sistema de plantio direto $(0,29 \mathrm{mg}-\mathrm{C} / \mathrm{m} 2 / \mathrm{h})$ em relação ao sistema de plantio convencional $(0,11 \mathrm{mg}-\mathrm{C} / \mathrm{m} 2 / \mathrm{h})$. Também se encontrou diferença no fluxo de óxido nitroso do plantio direto $(40,7 \mathrm{mg}-\mathrm{N} / \mathrm{m} 2 / \mathrm{h})$ que foi maior que o plantio convencional $(38,8 \mathrm{mg}-\mathrm{N} / \mathrm{m} 2 / \mathrm{h})$. Frente às mudanças no uso da terra cada vez mais frequentes, há a necessidade de novas formas de manejo que busquem reduzir as emissões desses gases ou aumentar seus sumidouros.

\section{Gaseous exchanges between methane and nitrous oxide between soil and atmosphere in different types of cover in western Pará, \\ Brazil}

\begin{abstract}
The change in land use and management has been occurring dynamically and intensely, especially in the Amazon region, which can result in a source or drain of greenhouse gases into the atmosphere. This work quantified the gas exchange of methane $(\mathrm{CH} 4)$ and nitrous oxide (N2O) between soil and atmosphere in different types of cover, and analyzed the environmental variables regulating the gas exchange in different microbasins of the western region of Pará state. carried out through field-installed chambers, subsequently analyzed by gas chromatography. There was no significant difference in methane flow through the effects of land use change on soybean $(0,23 \mathrm{mg}-\mathrm{C} / \mathrm{m} 2 / \mathrm{h})$, pasture $(0,31 \mathrm{mg}-\mathrm{C} / \mathrm{m} 2 / \mathrm{h})$ and capoeira $(0,42 \mathrm{mg}-\mathrm{C} / \mathrm{m} 2 / \mathrm{h})$. Statistical difference was found between the nitrous oxide flux related to the type of soil cover, where the capoeira flow $(19,57 \mathrm{mg}-\mathrm{N} / \mathrm{m} 2 / \mathrm{h})$ was lower than the pasture $(36,81 \mathrm{mg}-\mathrm{N} / \mathrm{m} 2 / \mathrm{h})$ and agriculture $(40,08 \mathrm{mg}-\mathrm{N} / \mathrm{m} 2 / \mathrm{h})$ There was a difference between the methane fluxes found in soybean in no-tillage system $(0,29 \mathrm{mg}-\mathrm{C} / \mathrm{m} 2 / \mathrm{h})$ in relation to the conventional tillage system $(0,11 \mathrm{mg}$ $\mathrm{C} / \mathrm{m} 2 / \mathrm{h})$. There was also a difference in nitrous oxide flow from no-till $(40,7 \mathrm{mg}-\mathrm{N} / \mathrm{m} 2 / \mathrm{h})$ that was higher than conventional tillage $(38,8 \mathrm{mg}-\mathrm{N} / \mathrm{m} 2 / \mathrm{h})$. Faced with increasingly frequent land use changes, there is a need for new forms of management that seek to reduce emissions of these gases or increase their sinks.
\end{abstract}

Keywords: Trace gases; Methane; Nitrous oxide; Change in land use.

Topic: Ciências do Solo

Reviewed anonymously in the process of blind peer.
Received: 01/07/2018 Approved: 12/07/2018
Fabiane Campos dos Santos

Universidade Federal do Oeste do Pará, Brasil

http://lattes.cnpq.br/7863681092001641

raimundo.oliveira-junior@embrapa.br

Quêzia Leandro de Moura Guerreiro (iD)

Universidade Federal do Oeste do Pará, Brasil

http://lattes.cnpq.br/2392493799166491

http://orcid.org/0000-0002-4382-1250

queziamoura@hotmail.com

Raimundo Cosme de Oliveira Júnior

Embrapa Amazônia Oriental, Brasil

http://lattes.cnpq.br/6425044612146340

raimundo.oliveira-junior@embrapa.br

DOI: 10.6008/CBPC2179-6858.2018.006.0001

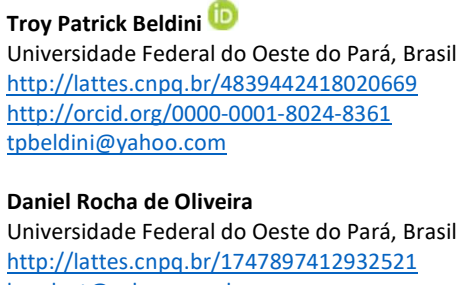

Referencing this:

SANTOS, F. C.; GUERREIRO, Q. L. M.; OLIVEIRA JÚNIOR, R. C.; BELDINI, T. P.; OLIVEIRA, D. R.. Trocas gasosas entre metano e óxido nitroso entre solo e atmosfera em diferentes tipos de cobertura na região oeste do Pará, Brasil. Revista Ibero Americana de Ciências Ambientais, v.9, n.6, p.1-13, 2018. DOI:

http://doi.org/10.6008/CBPC2179-6858.2018.006.0001 


\section{INTRODUÇÃO}

Na Amazônia, a abertura de novas áreas agrícolas e a utilização de fertilizantes nitrogenados associadas à prática de manejo pouco sustentáveis das áreas trabalhadas são responsáveis pela grande emissão de gases traço associados ao aquecimento global (LAURANCE et al., 2004). Entre os principais gases formadores do efeito estufa, destacam-se o dióxido de carbono $\left(\mathrm{CO}_{2}\right)$, o metano $\left(\mathrm{CH}_{4}\right)$, o óxido nitroso $\left(\mathrm{N}_{2} \mathrm{O}\right)$, o ozônio $\left(\mathrm{O}_{3}\right)$ e o vapor d'água $\left(\mathrm{H}_{2} \mathrm{O}\right)$ (OSTERMAYER, 2004).

Os sistemas de manejo que apresentam altas concentrações de resíduos vegetais na superfície, maior adensamento superficial (agricultura mecanizada) e maior atividade biológica, como os solos sob sistema de plantio direto, apresentam condições mais propícias para emissão de óxido nitroso. As emissões em latossolos sob diferentes rotações de culturas apresentaram valores muito baixos tanto no sistema de plantio direto quanto no plantio convencional (JANTALIA et al., 2008).

Dentro da região Oeste do Estado do Pará, uma frente de expansão agrícola se estabelece, na qual, a soja é precedida pela pastagem ou pela plantação de arroz. As áreas sobre pastos degradados são preferidas em relação a áreas de floresta uma vez que o custo do processo de limpeza é inexistente ou muito baixo. Devido às áreas serem pobres em nutrientes alguns espaços são abandonados formando as chamadas capoeiras. Entender como os processos e os controles ambientais variam entre florestas nativas, áreas agrícolas, capoeira e pastagem são cruciais para identificar os fatores que podem contribuir para o desenvolvimento de usos do solo.

Alguns estudos com fluxo de gases, como os de Davidson et al. (2004), Keller et al. (2005) e Sampaio et al. (2006), já foram realizados em municípios dessa região (Santarém e Belterra), porém, em áreas especificas, sem avaliar diferentes usos da terra. Sampaio et al. (2006) demostrou que o fluxo de metano em áreas de cultivo de soja e arroz foi quantitativamente menor do que o fluxo na área de floresta. Os solos de todos os sítios pesquisados apresentaram fluxo negativo e a umidade e a temperatura do solo não foram eficientes controladores do fluxo de metano. No estudo de Davidson et al. (2004), realizado na Floresta Nacional do Tapajós, os dados demonstraram que nas condições mais secas do solo ocorreu inibição do óxido nitroso e aumento das taxas de consumo de metano na atmosfera.

Estudos sobre esses gases na região Amazônica são extremamente limitados e a variabilidade de condições edáficas e de clima é muito extensa, exigindo maiores esforços na tentativa de se entender como ocorrem essas alterações dentro da região. Nesse âmbito, a presente pesquisa teve como objetivo avaliar a influência da conversão de áreas em diferentes usos da terra sobre os fluxos de metano e óxido nitroso nos municípios de Belterra e Santarém, Pará.

\section{MATERIAIS E MÉTODOS}

\section{Área de estudo}

As áreas de estudo estão localizadas na região Oeste do Estado do Pará e abrangem as cidades de Belterra e Santarém (Figura 1). De acordo com IBAMA (2004), o clima da região é do tipo Ami (classificação 
de Köppen). O solo predominante é o latossolo, que ocorre em relevo plano a suavemente ondulado e sua textura pode variar de arenosa a muito argilosa (MORAES et al., 1995).

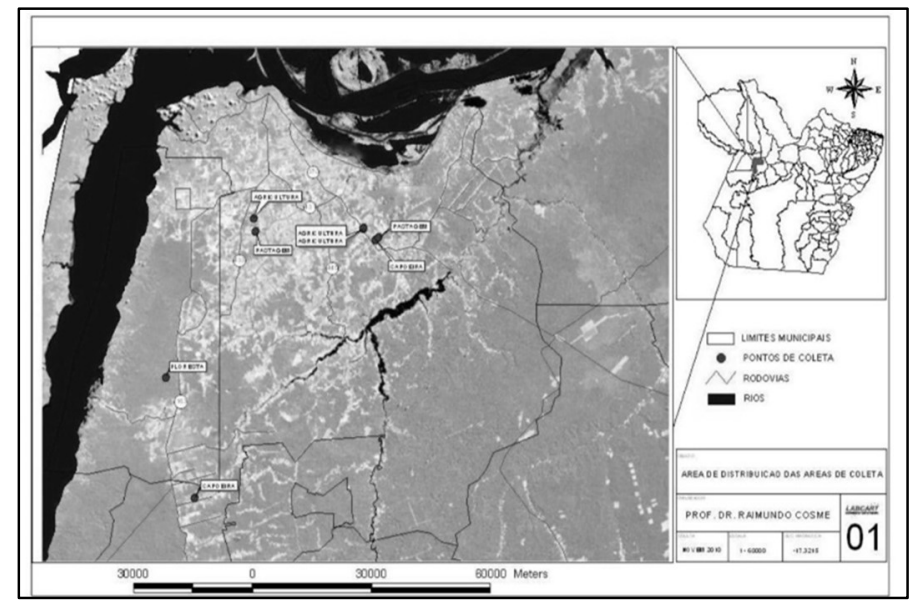

Figura 1: Localização das áreas de estudo na região Oeste do Estado do Pará.

$\mathrm{Na}$ cidade de Belterra, a temperatura média anual varia de 25 a $28^{\circ} \mathrm{C}$, com umidade relativa média do ar de $86 \%$ durante quase todos os meses do ano. A precipitação total anual deste município é de 1909 $\mathrm{mm}$, sendo a média mensal no período mais seco de $62,5 \mathrm{~mm}$ e $770 \mathrm{~mm}$ de média no período mais chuvoso de fevereiro a junho (INMET, 2010).

Em termos de temperatura do ar, Santarém apresenta uma pequena variabilidade anual, estando às médias, oscilando entre $25,4^{\circ} \mathrm{C}$ e $27,1^{\circ} \mathrm{C}$. Os valores de umidade relativa do ar são elevados durante o ano todo, sendo a média de $86,7 \%$. O elemento meteorológico que apresenta maior variabilidade anual é a precipitação pluvial, sendo essa região caracterizada por apresentar dois períodos bem distintos: um chuvoso, que vai de dezembro a maio, e outro menos chuvoso, que se estende de julho a novembro. Os valores médios anuais oscilam em torno de 1920mm (INMET, 2010).

Este trabalho faz parte do projeto 'Sustentabilidade dos Usos da Terra na Amazônia', que tem como tema central o entendimento e previsão de respostas da biodiversidade a mudanças ambientais. As áreas do entorno de Santarém (microbacias) foram selecionadas em função da facilidade de acesso, parceria com os produtores locais e da cobertura florestal remanescente. Essas áreas formam um gradiente de intensificação de uso da terra incorporando quatro diferentes usos da terra (floresta, capoeira, área de agricultura e pastagem).

O estudo foi conduzido em três microbacias do projeto, denominadas de B112, B129 e B357, onde selecionou-se áreas de capoeira, pastagem e agricultura próximas a BR-163 e a PA-370. Foram amostrados sete transectos (sítios), sendo três sob uso agrícola com cultura de soja (dois em plantio convencional e um em plantio direto), dois sob pastagem e dois sob capoeira, notável na tabela 1.

As áreas de campo agrícolas em sistema de plantio direto são submetidas à rotação de culturas (soja e milho), já o campo agrícola com sistema convencional é utilizado com cultivo de soja há mais de 10 anos, as pastagens estão ativas e são manejadas de acordo com índices técnicos da pecuária e as áreas de capoeira possuem aproximadamente 15 anos. Para as áreas de capoeira e pastagem foram feitas duas coletas em cada sítio com nove repetições em cada transecto, nos meses fevereiro, março e abril de 2011 (período chuvoso). 
Tabela 1: Identificação dos pontos de coleta e suas respectivas descrições.

\begin{tabular}{|c|c|l|}
\hline MICROBACIA (B) & TRANSECTO (T) & USO DA TERRA \\
\hline \multirow{3}{*}{112} & 1 & Campo agrícola (plantio direto) \\
\cline { 2 - 3 } & $1 \mathrm{~b}$ & Campo agrícola (plantio convencional) \\
\cline { 2 - 3 } & 3 & Capoeira \\
\cline { 2 - 3 } & 7 & Pastagem ativa \\
\hline \multirow{2}{*}{129} & 9 & Campo agrícola Plantio direto \\
\cline { 2 - 3 } & 7 & Pastagem ativa \\
\hline \multirow{2}{*}{357} & 3 & Capoeira \\
\hline
\end{tabular}

Nas áreas de agricultura, levou-se em consideração o ciclo da cultura, com o intuito tanto de fazer a comparação entre plantio direto e plantio convencional, como a sequência da cultura da soja, o que possibilitou a coleta de dados antes do plantio, no plantio, uma semana após o plantio (período intermediário) e na colheita. Na área B112T1 (soja em plantio direto) foram feitas 12 coletas, na área B112T1b (soja em plantio convencional) 10 coletas e na área B129T9 (soja em plantio direto) 8 coletas, essas representam os meses de dezembro de 2010 a junho de 2012.

\section{Sistema de amostragem e análises laboratoriais}

Para as medidas de fluxo de metano e óxido nitroso nos sítios de pastagem, capoeira e sob uso agrícola com cultivo de soja, foi estabelecido um transecto em cada área. $\mathrm{O}$ transecto é uma reta de $300 \mathrm{~m}$ de comprimento, formada por três pontos $(0,150$ e $300 \mathrm{~m})$, onde em cada ponto foram instaladas três câmeras para a medida de fluxo de gases. Essas câmaras foram instaladas a aproximadamente $5 \mathrm{~m}$ de distância do ponto principal, totalizando 9 câmaras por transecto.

Os fluxos de metano e óxido nitroso foram coletados por meio de câmaras de concentração utilizadas manualmente. As amostras de gás do solo foram coletadas em intervalos de 1 a 30 minutos em seringas de nylon de $20 \mathrm{~mL}$. A câmara fechada restringe a passagem de ar liberado do solo para a atmosfera, assim as medidas demonstram as mudanças de concentrações do gás num intervalo de tempo.

O material usado na construção das câmaras foi o cloreto de polivinil (PVC), tendo como vantagens seu baixo custo, facilidade de manuseio, menor aquecimento devido a coloração branca e boa durabilidade no campo. A câmara era de formato cilíndrico com $22 \mathrm{~cm}$ de altura por $25 \mathrm{~cm}$ de diâmetro. A face superior da câmara possuía dois orifícios vedados com rolha de silicone e um dos orifícios era atravessado por uma agulha hipodérmica acoplada a uma válvula de polipropileno (utilizado para a retirada da amostra) o outro orifício era ligado a um tubo de borracha (para manter a pressão interna da câmara igual a atmosférica).

Assentava-se a câmara de PVC sobre o anel para proporcionar a vedação da câmara estática. Em seguida se coletava a primeira amostra de ar (tempo 1 - 1 minuto) com uma seringa de polipropileno de $20 \mathrm{~mL}$ equipada com uma válvula de fechamento no orifício de saída. Essa primeira amostra representa a concentração atmosférica no momento da amostragem. A segunda amostra (tempo 10) foi coletada 10 minutos após, utilizando-se o mesmo tipo de seringa. A terceira (tempo 20) e a quarta (tempo 30) amostras foram coletadas aos 20 e 30 minutos, respectivamente, seguindo-se o mesmo procedimento. Para garantir homogenização do ar dentro da câmara, antes de cada amostragem, o ar da câmara era aspirado e injetado 
pela seringa por três vezes. As amostras de gás foram transportadas para o laboratório da Embrapa em Santarém onde foram analisadas por cromatografia gasosa num intervalo de 36 horas após a coleta.

Para as medidas de temperatura do solo, foi utilizado um termômetro digital da marca Taylor que foi introduzido no solo a profundidade de $2 \mathrm{~cm}$, ao lado de cada uma das câmaras. O mesmo sensor é usado para fazer a leitura da temperatura do ar a sombra no momento da amostragem dos gases; paralelo a isso foi feito medidas de altura para cada câmara com auxílio de régua.

Do interior das câmaras retiraram-se amostras de solo a $10 \mathrm{~cm}$ de profundidade que foram acondicionados em sacos plásticos devidamente identificados e posteriormente conduzidos ao laboratório de Química da Universidade do Oeste do Pará para pesagem. As amostras foram pesadas em balança de precisão para a obtenção do peso úmido de cada amostra de solo. Para determinar o peso seco foi utilizado o método de secagem em estufa a $105^{\circ} \mathrm{C}$ por 48 horas, resultando na umidade gravimétrica do solo, ou seja, o percentual de água no solo por meio da equação Umidade $(\%)=(\mathrm{Pu}-\mathrm{Ps}) /(\mathrm{Ps}) * 100$, onde: $\mathrm{Pu}=$ Peso úmido do solo; e Ps= Peso seco do solo.

Os espaços porosos do solo preenchidos por água (water filled por espace- WFPS) foi calculado a partir da densidade global do solo (dg), da densidade das partículas (dp) e do teor de água no solo (u), segundo as equações $\theta(\%)=(u \cdot d g) * 100 ; \alpha(\%)=(1-(d g / d p)) * 100 ;$ e WFPS $(\%)=(\alpha / \theta) * 100$, onde: $\theta=$ umidade do solo (\%); $\alpha=$ espaço poroso do solo (\%); $d \mathrm{~g}=$ densidade global do solo $\left(\mathrm{g} / \mathrm{cm}^{-3}\right) ; \mathrm{dp}=$ densidade das partículas $\left(\mathrm{g} \mathrm{cm}^{-3}\right) ; \mathrm{u}=$ teor de água no solo (\%).

O fluxo foi calculado pela taxa de mudança de concentração com base na Primeira Lei de Fick ( $F=p$ $(V / A)(d C / d t))$ e a densidade do ar será calculada $\left(p=P / c^{*} T\right)$, onde: $F$ = fluxo de metano emitido na superfície do solo; $p$ = densidade do ar ajustada à temperatura do ar no momento da amostragem; $V=$ volume interno da câmara acima da superfície do solo; $A$ = área superficial do solo encoberta pela câmara; $d C / d t$ = inclinação da curva de variação de concentração do gás em função do tempo; c = constante universal dos gases $\left(0,083 \mathrm{l} \cdot \mathrm{atm} \cdot \mathrm{mol}^{-1} \cdot \mathrm{k}^{-1}\right) ; \mathrm{T}=$ temperatura do ar em Kelvin; e $\mathrm{P}=$ pressão total em atm. Fatores ambientais que regulam as taxas de troca gasosa entre solo e atmosfera foram coletados, medidos e correlacionados com os fluxos obtidos. Entre essas variáveis está a textura do solo (argiloso ou arenoso), temperatura e a quantidade de água no solo.

\section{Análises estatísticas}

Para testar a normalidade dos dados de fluxos de metano, óxido nitroso, temperatura, umidade e WFPS, foi utilizado o teste de Kolmogorov-Smirnoff. Em seguida foi aplicada a análise de variância (ANOVA) e posteriormente submetidos ao teste de Tukey (5\%) para a determinação das diferenças entre as médias dos fluxos. Com o intuito de saber se existe relação entre o fluxo de metano e óxido nitroso com as demais variáveis, temperatura, umidade e WFPS, foram utilizadas análises de regressão linear. A significância foi determinada ao nível de 95\%. Os testes estatísticos foram realizados através do software Statitica 7. 


\section{DISCUSSÃO TEÓRICA}

\section{Variáveis ambientais}

Os valores de umidade do solo nas três áreas agrícolas amostradas não diferiram estatisticamente entre si $(p>0,05)$, o mesmo ocorreu para as áreas de capoeira e pastagem. Os valores de umidade do solo foram significativamente $(p<0,05)$ maiores na área de capoeira em relação a área de agricultura e pastagem que também se diferenciaram entre si $(P<0,05)$, conforme se pode visualizar na tabela 2 . Médias seguidas por letras diferentes se diferem estatisticamente entre si pelo teste Tukey a 5\% de probabilidade.

Tabela 2: Umidade do solo nos diferentes usos da terra.

\begin{tabular}{|l|c|c|}
\hline TRATAMENTO & UMIDADE (\%) & ERRO PADRÃO \\
\hline Agricultura & $30,8 \mathbf{a}$ & 0,6 \\
\hline Pastagem & $20,4 \mathbf{b}$ & 2,3 \\
\hline Capoeira & $46,3 \mathbf{~ c}$ & 2,2 \\
\hline
\end{tabular}

As temperaturas do ar para os transectos de agricultura amostrados (B112T1, B112T1b e B129T9) não diferiram estatisticamente entre si $(p>0,05)$, ilustrados nas figuras $2 A, 2 B$ e $2 C)$. 0 mesmo resultado foi encontrado quando se comparou os transectos da pastagem (B112T7 e B129T7) e de capoeira (B112T3 e B357T3). Quando se comparou a temperatura do ar da área de capoeira com a de pastagem (Figura 2D), se encontrou diferenças significativas $(p<0,05)$.

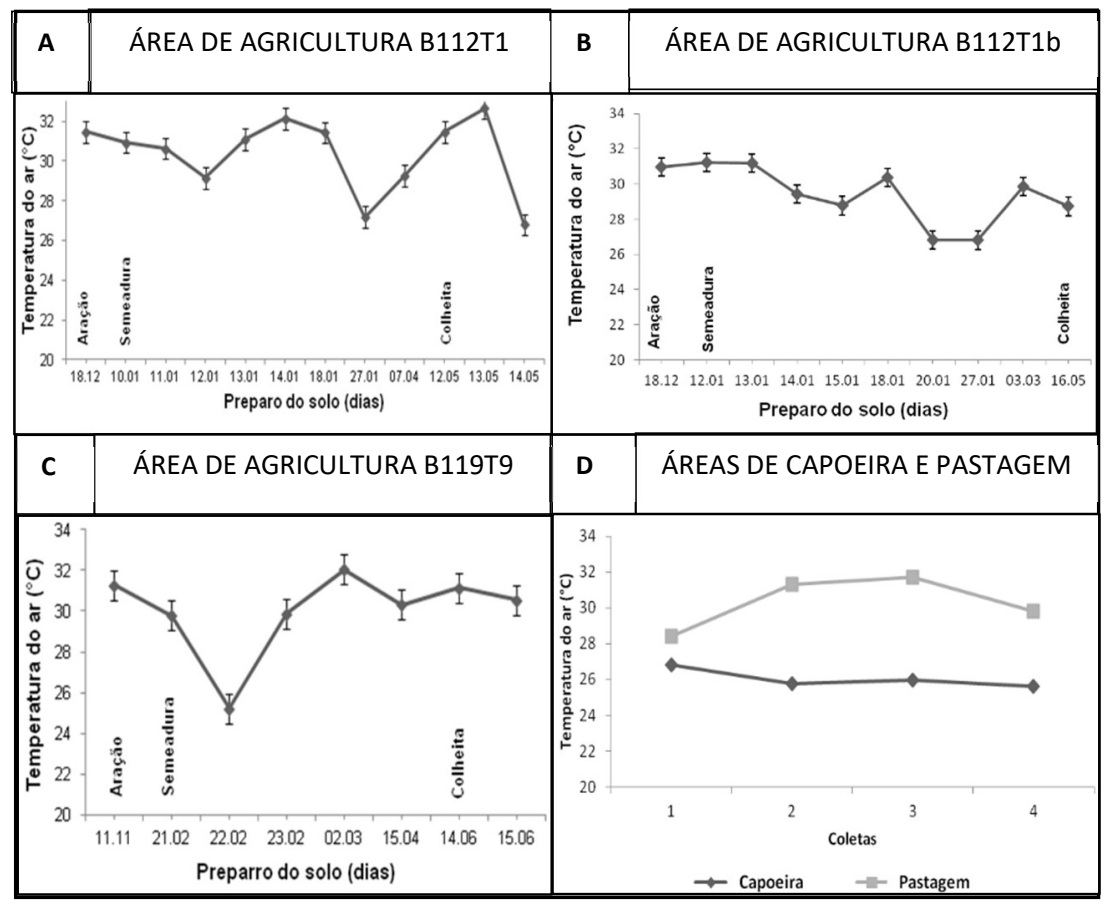

Figura 2: Temperatura média do ar nas áreas: A) agricultura de plantio direto (B112T1;), B) agricultura de plantio convencional (B112T1b); C) agricultura de plantio direto (B129T9); e D) áreas de capoeira e pastagem, durante o período de avaliação (dia.mês).

Comparando as áreas de agricultura, pastagem e capoeira, os valores de temperatura do ar na segunda foram estatisticamente menores $(p<0,05)$ que as demais. Os valores médios encontrados foram $29,9^{\circ} \mathrm{C}( \pm 0,4)$ na agricultura, $26^{\circ} \mathrm{C}( \pm 0,2)$ na capoeira e $30,3^{\circ} \mathrm{C}( \pm 0,7)$ na pastagem. Os valores de temperatura do solo nos três transectos da agricultura (figuras $3 A$, $3 B$ e $3 C$ ) foram significativamente $(p<0,05)$ menores na área de coleta B129T9 em relação às outras áreas, as quais não apresentaram diferença entre si. Analisando 
a temperatura do solo na área de agricultura, pastagem e capoeira, as temperaturas na capoeira foram estatisticamente menores $(p<0,05)$ que as demais. Os valores médios encontrados foram de $24,95^{\circ} \mathrm{C}( \pm 0,1)$ na capoeira, $28,6^{\circ} \mathrm{C}( \pm 0,7)$ na pastagem e $28,8^{\circ} \mathrm{C}( \pm 0,3)$ na agricultura.

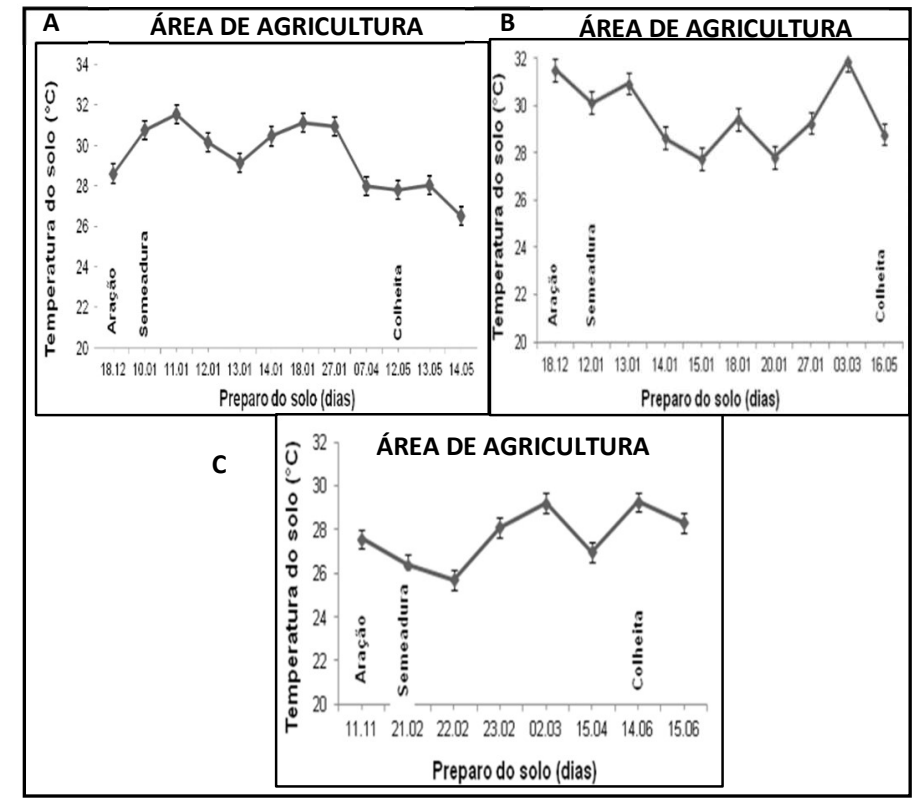

Figura 3: Temperatura média do solo nas áreas: A) agricultura de plantio direto (B112T1); B) agricultura de plantio convencional (B112T1b); e C) agricultura de plantio direto (B129T9), durante o período de avaliação (dia.mês). Fluxos de metano e óxido nitroso.

Na área de agricultura com a soja em sistema de plantio direto (B112T1) houve diferença significativa para os fluxos de metano no ciclo da cultura de soja, onde os fluxos médios encontrados variaram de 0,0032 $\pm 0,0016 \mathrm{mg}-\mathrm{C} / \mathrm{m}^{2} / \mathrm{h}$ até $1,3962 \pm 0,91 \mathrm{mg}-\mathrm{C} / \mathrm{m}^{2} / \mathrm{h}$, conforme se vê na figura $4 \mathrm{~A}$. Na área de agricultura com a soja em sistema de plantio direto (B129T9) comparando-se as medidas em diferentes períodos do estágio da cultura constatou-se diferenças significativas $(p<0,05)$, ou seja, os fluxos de metano encontrados na colheita foram diferentes dos demais fluxos (Figura 4B). A variação dos fluxos médios foram de 0,0157 $\pm 0,0032 \mathrm{mg}$ $\mathrm{C} / \mathrm{m}^{2} / \mathrm{h}$ até $1,6002 \pm 0,2278 \mathrm{mg}-\mathrm{C} / \mathrm{m}^{2} / \mathrm{h}$.

Nos dois transectos de plantio direto percebe-se um aumento no fluxo de metano próximo da época da colheita e na colheita; uma possível explicação é que neste período devido ao aumento de material vegetal no solo, a atividade microbiana esteja mais acelerada. A análise de variância não identificou diferença significativa entre os fluxos de metano encontrados no transecto de soja em sistema de plantio convencional (B112T1b). Estatisticamente, o fluxo de metano das áreas com plantio direto (B112T1 e B129T9) não se diferenciou. Mas, quando comparando o plantio direto $\left(0,29 \mathrm{mg}-\mathrm{C} / \mathrm{m}^{2} / \mathrm{h}\right)$ com o plantio convencional $\left(0,11 \mathrm{mg}-\mathrm{C} / \mathrm{m}^{2} / \mathrm{h}\right)$ constataram-se diferenças significativas $(\mathrm{p}<0,05)$.

Segundo Gomes (2006), o plantio direto quando associado a sistemas com leguminosas ou gramíneas tendem a apresentar uma tendência de baixa taxa de absorção de metano, enquanto o plantio convencional se caracterizou como emissor de metano. Para a área de capoeira não se encontrou diferença entre a primeira e a segunda medida em cada transecto. Comparando-se os dois transectos de capoeira (B112T3 e B357T3) os fluxos foram iguais. Dessa maneira, o fator espaço não foi determinante para a diferenciação nos 
fluxos $\left(0,42 \pm 0,2 \mathrm{mg}-\mathrm{C} / \mathrm{m}^{2} / \mathrm{h}\right)$, pois um dos transectos se encontra na microbacia 112 (PA-370) e o outro na microbacia 357 (BR-163).

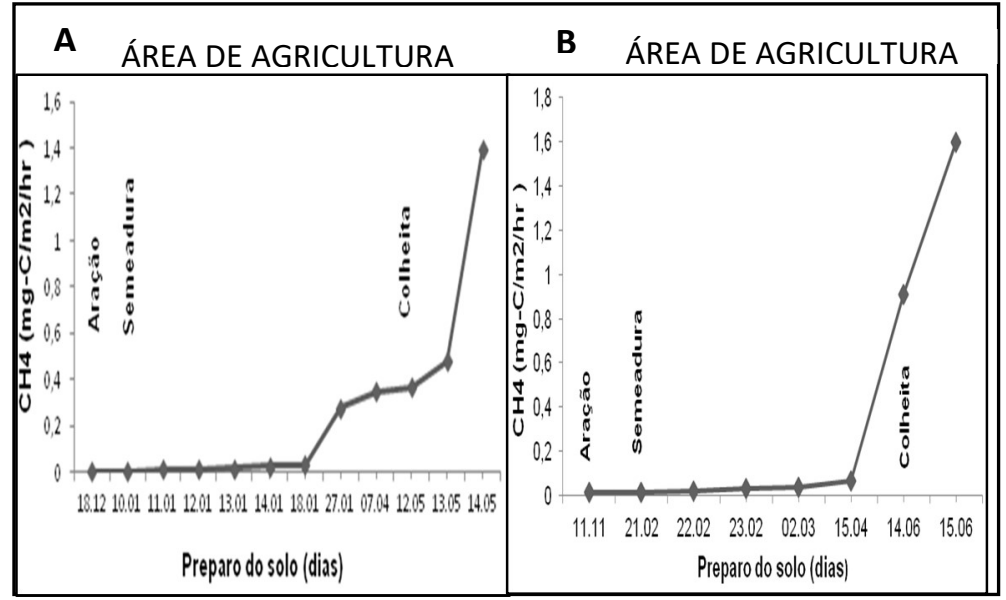

Figura 4: Medidas de fluxos de metano $\left(\mathrm{CH}_{4}\right)$ em diferentes períodos do plantio nas áreas: A) agricultura B112T1; e B) agricultura B119T9.

Na área de pastagem não houve diferença entre a primeira e a segunda medida em cada transecto. Comparando o transecto B112T7 com o B129T7, constatou-se diferenças significativas ( $p>0,05)$, onde o fluxo médio da área B112T7 foi $0,21 \pm 0,18 \mathrm{mg}-\mathrm{C} / \mathrm{m}^{2} / \mathrm{h}$ e o da área $\mathrm{B} 129 T 70,05 \pm 0,03 \mathrm{mg}-\mathrm{C} / \mathrm{m}^{2} / \mathrm{h}$. As três áreas (Agricultura, Pastagem e Capoeira), não apresentaram diferença significativa $(p>0,05)$ entre os fluxos, ou seja, estatisticamente a cobertura vegetal não ocasionou uma variação no fluxo de metano, que foi proposto na tabela 3.

Tabela 3: Dados da análise de variância obtidos para os três tipos de uso da terra em relação ao fluxo de metano.

\begin{tabular}{|c|c|c|c|c|c|c|}
\hline Tipos de uso & Fonte de variação & Soma de quadrados & Graus de liberdade & Quadrado Médio & $F_{\text {calculado }}$ & p-valor \\
\hline \multirow{3}{*}{ Capoeira } & Entre Grupos & 0,000 & 1 & 0,000 & & \\
\hline & Dentro do Grupo & 0,002 & 15 & 0,000 & 0,033 & 0,858 \\
\hline & Total & 0,002 & 16 & & & \\
\hline \multirow{3}{*}{ Agricultura } & Entre Grupos & 0,488 & 1 & 0,488 & & \\
\hline & Dentro do Grupo & 30,767 & 14 & 2,198 & 0,222 & 0,645 \\
\hline & Total & 31,225 & 15 & & & \\
\hline \multirow{3}{*}{ Pastagem } & Entre Grupos & 0,760 & 1 & 0,760 & & \\
\hline & Dentro do Grupo & 31,482 & 14 & 2,249 & 0,338 & 0,570 \\
\hline & Total & 32,242 & 15 & & & \\
\hline
\end{tabular}

Existe correlação significativa e negativa entre o fluxo de metano e temperatura do solo na área de agricultura com soja (B112T1) (figura 5A). À medida que a temperatura aumenta, maior é a oxidação de metano pelo solo, isso se deve à temperatura, pois é um fator que pode aumentar a atividade de microrganismos do solo que consequentemente aumentarão a oxidação de metano em ambiente aeróbico.

Em estudo realizado por Moura (2010) na Floresta Nacional do Tapajós, Oeste do Pará, o fluxo de metano variou de $-4,69$ a 4,00mg $\mathrm{CH}_{4} / \mathrm{m}^{-2} \mathrm{~d}^{-1}$, e a média foi de $-1,17(0,28) \mathrm{mg} \mathrm{CH}_{4} / \mathrm{m}^{-2} \mathrm{~d}^{-1}$, indicando consumo de metano pelo solo, devido fluxo negativo na maioria das medidas amostradas. Na área de agricultura B112T1b e B129T9 não houve correlação significativa entre o fluxo de metano e a temperatura do solo. Na pesquisa de Sampaio et al. (2006), em área de plantação de soja, a média do fluxo de metano encontrado foi de $-1,2 \pm 1,7 \mathrm{mg} \mathrm{CH}_{4} / \mathrm{m}^{2} / \mathrm{h}$, e os dados de umidade e temperatura do solo não se correlacionaram com o fluxo. 


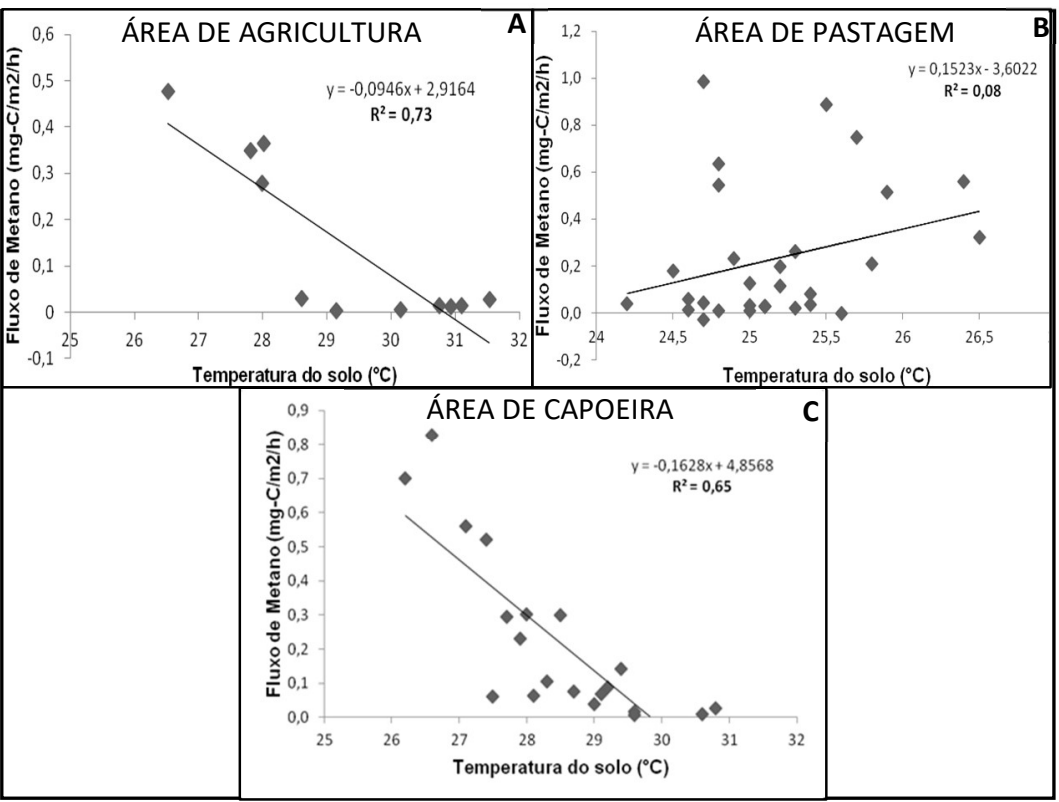

Figura 5: Correlação entre os dados de temperatura do solo e fluxo de metano para as áreas: A) agricultura B112T1; B) Pastagem; e C) Capoeira.

Não houve correlação significativa entre o fluxo de metano e porcentagem de poros do solo preenchidos por água na área de agricultura B112T1 $\left(R^{2}=0,052\right), B 112 T 1 b\left(R^{2}=0,13\right)$ e B129T1 $\left(R^{2}=0,008\right)$; inclusive na área de pastagem $\left(R^{2}=0,25\right)$ e capoeira $\left(R^{2}=0,30\right)$. Na área de agricultura com soja e sistema de plantio direto (B112T1), houve diferença significativa para os fluxos de óxido nitroso na colheita da cultura, ou seja, o fluxo foi maior na colheita levando-se em consideração todo o ciclo.

$\mathrm{Na}$ área de agricultura com soja em sistema de plantio direto (B129T9), comparando-se as medidas em diferentes períodos do estágio da cultura constatou-se diferenças significativas $(p<0,05)$, ou seja, os fluxos de óxido nitroso encontrados na colheita foram diferentes dos demais fluxos. Na área com plantio de soja e sistema convencional (B112T1b) encontraram-se diferenças significativas entre o plantio, a segunda semana de plantio e a colheita. O fluxo de óxido nitroso foi maior na colheita da soja (Tabela 4). Médias seguidas pela mesma letra na coluna não se diferem entre si pelo teste Tukey a $5 \%$ de probabilidade. EP, no contexto da tabela 4, significa 'Erro padrão'.

Tabela 4: Fluxo médio de óxido nitroso $\left(\mathrm{mg}-\mathrm{N} / \mathrm{m}^{2} / \mathrm{h}\right)$ durante o ciclo da soja em diferentes áreas.

\begin{tabular}{|l|c|c|c|c|c|c|}
\hline PERÍODO DA COLETA & B112T1 & EP & B129T9 & EP & B112T1B & EP \\
\hline Antes do plantio & $18,94 a$ & 3,68 & $11,28 a$ & 3,76 & $32,45 a b$ & 14,25 \\
\hline Plantio & $23,45 a$ & 5,34 & $45,24 a b$ & 7,03 & $10,6 a$ & 3,11 \\
\hline Semana após plantio & $23,45 a$ & 9,25 & $31,36 a b$ & 8,80 & $15,56 a$ & 4,16 \\
\hline Intermediário & $31,38 \mathrm{a}$ & 5,70 & $16,12 \mathrm{a}$ & 1,91 & $43,80 \mathrm{ab}$ & 13,92 \\
\hline Colheita & $108,23 \mathrm{~b}$ & 30,92 & $96,57 \mathrm{c}$ & 20,55 & $91,55 \mathrm{c}$ & 29,29 \\
\hline
\end{tabular}

Eram esperados maiores valores de fluxos de óxido nitroso nas primeiras medidas realizadas, pois trabalhos como os de Matson et al. (1996) mostram que os picos de fluxo de óxido nitroso apresentam-se nos primeiros dias devido a fertilização e depois se mantém constante. Uma provável explicação para um decréscimo no fluxo na coleta realizada no período intermediário da área B129T9, é que neste momento as plantas já estavam todas formadas (cheias de folhas, vagens e caules bem desenvolvidos), de modo que a atividade bacteriana se tornou muito baixa. 
O valor de fluxo de óxido nitroso relativamente alto na área B112T1 pode ser atribuído a uma maior atividade microbiológica, pois o solo apresentava-se bastante úmido devido a uma chuva forte no dia anterior. A análise de variância demonstrou que não existe diferença significativa entre o fluxo de óxido nitroso nas distintas áreas de plantio direto (B112T1 e B129T9). Mas existe diferença entre o fluxo do sistema de plantio direto $\left(40,7 \mathrm{mg}-\mathrm{N} / \mathrm{m}^{2} / \mathrm{h}\right)$ com o sistema de plantio convencional $\left(38,8 \mathrm{mg}-\mathrm{N} / \mathrm{m}^{2} / \mathrm{h}\right.$, ou seja, o sistema adotado influenciou o fluxo do óxido nitroso no cultivo de soja.

As maiores emissões em plantio direto em relação ao plantio convencional encontradas neste estudo já foram reportadas anteriormente por outros autores (PAVEI, 2005; LIU et al., 2006; GOMES, 2006; ESCOBAR, 2007; ZANATTA et al., 2008) que atribuíram os resultados a compactação ou aos espaços porosos do solo preenchidos por água, o que reduziria a difusão de $\mathrm{O}_{2}$ no solo, e a maior atividade microbiana que consumiria $\mathrm{O}_{2}$ e criaria sítios de anaerobiose, favorecendo a produção de óxido nitroso por desnitrificação.

Resultado diferente foi encontrado por Carvalho et al. (2006), que realizou estudos da emissão de óxidos de nitrogênio em Planaltina (DF) e não encontraram diferenças significativas para emissões de óxido nitroso entre sistema de plantio direto com palhada de soja, mais mucuna-preta e milheto, e plantio convencional com aração e gradagem. Carvalho et al. (2006) considerara que houve rápida decomposição das palhadas de leguminosas e, consequentemente, baixo acúmulo de resíduos. No entanto, eles observaram acentuada variabilidade dos dados, com altos desvios em relação à média, o que pode ter contribuído para que não houvesse diferença significativa entre os tratamentos.

Os fluxos de óxido nitroso são bastante variáveis quando se compara diferentes culturas e mesmo considerando a mesma cultura. Os resultados dessa natureza reforçam e validam a ideia proposta por Mosier (1990), de que as interações entre as variáveis físicas, químicas e biológicas são muito complexas, tornandose necessário um número maior de trabalhos experimentais para melhor caracterizar a emissão de óxido nitroso pela agricultura, pois cada cultura tem características próprias e reage de maneira diferente dependendo das condições ambientais.

Para a área de capoeira, não se encontrou diferença entre a primeira e a segunda medida, e comparando-se as duas áreas de capoeira (B112T3 e B357T3) os fluxos foram estatisticamente iguais, dados notável na tabela 5. Na área de pastagem não houve diferença entre a primeira e a segunda medida, e comparando-se as duas áreas (B112T7 e B129T7) os fluxos foram estatisticamente iguais. Médias seguidas pela mesma letra não se diferem entre si pela análise de variância a 5\% de probabilidade.

Tabela 5: Fluxo médio de óxido nitroso $\left(\mathrm{mg}-\mathrm{N} / \mathrm{m}^{2} / \mathrm{h}\right)$ para as áreas de capoeira.

\begin{tabular}{|l|c|c|}
\hline TRATAMENTO & MÉDIA Capoeira & ERRO PADRÃO \\
\hline B112T3 & $18,94 \mathrm{a}$ & 3,68 \\
\hline B357T3 & 20,02 a & 6,78 \\
\hline \multicolumn{3}{|c|}{ Pastagem } \\
\hline B112T7 & $35,51 \mathrm{a}$ & 20,9 \\
\hline B129T7 & $38,11 \mathrm{a}$ & 7,2 \\
\hline
\end{tabular}

O resultado da análise de variância indicou diferenças significativas entre os fluxos óxido nitroso, ou seja, estatisticamente, o tipo de cobertura do solo (Agricultura, Pastagem e Capoeira) ocasionou uma 
variação no fluxo, e de acordo com o teste Tukey, a cobertura que emitiu menor quantidade de fluxo de óxido nitroso foi a capoeira (tabela 6). Médias seguidas pela mesma letra não se diferem entre si pelo teste Tukey a $5 \%$ de probabilidade.

Tabela 6: Fluxo médio de óxido nitroso $\left(\mathrm{mg}-\mathrm{N} / \mathrm{m}^{2} / \mathrm{h}\right)$ para as diferentes áreas.

\begin{tabular}{|c|c|c|}
\hline TRATAMENTO & MÉDIA & ERRO PADRÃO \\
\hline Agricultura & $40,08 \mathbf{a}$ & 1,30 \\
\hline Capoeira & $19,57 \mathbf{b}$ & 0,76 \\
\hline Pastagem & $36,81 \mathbf{a}$ & 1,84 \\
\hline
\end{tabular}

Foi obtido correlação significativa e negativa entre o óxido nitroso e a temperatura do solo na área de agricultura B112T1 (figura 6A). Na área de agricultura B112T1b, não houve correlação significativa entre o fluxo de metano e a temperatura do solo. O fluxo de óxido nitroso se relacionou com a temperatura do solo na área de agricultura B129T9 (figura 6B).

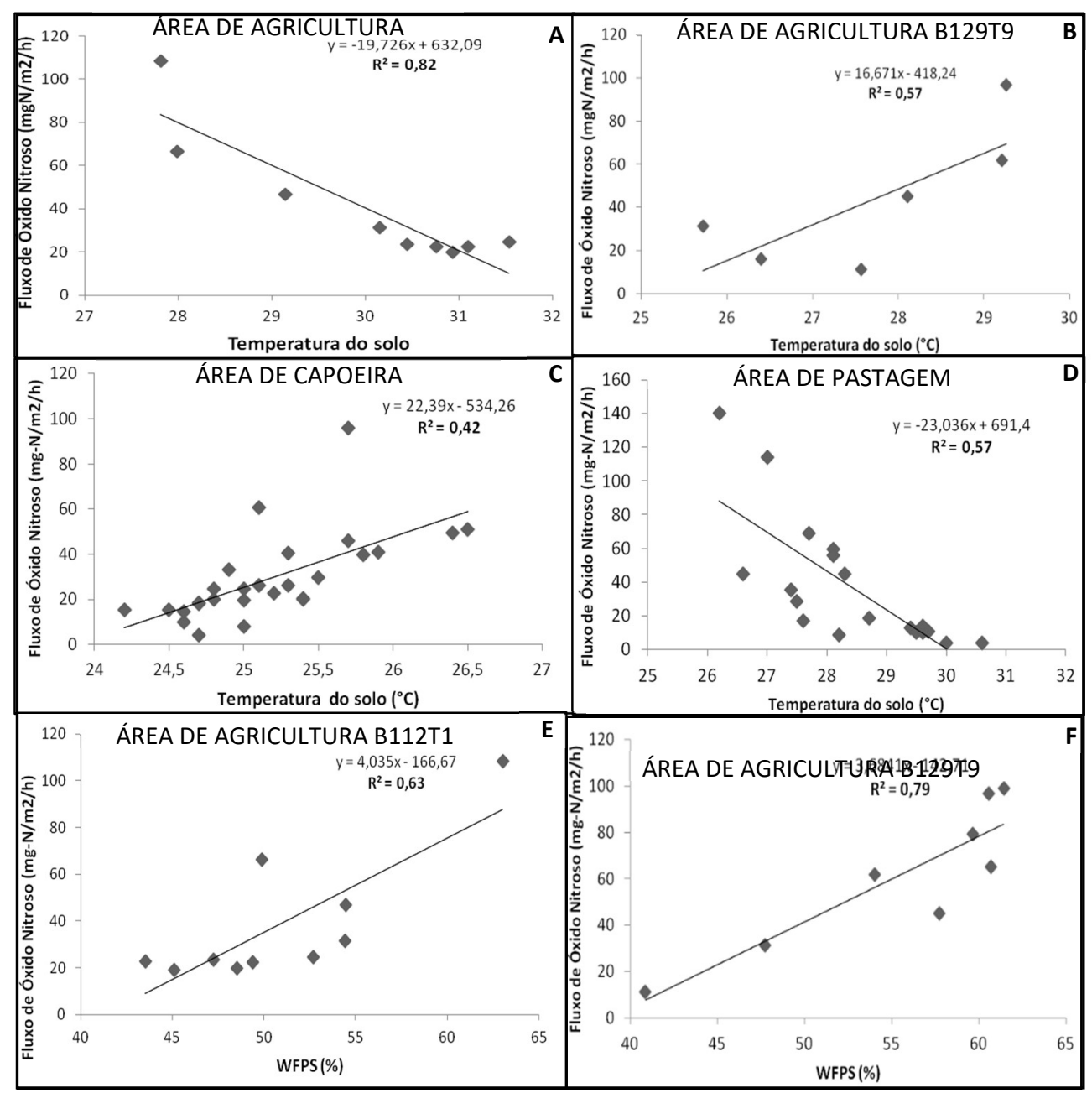

Figura 6: Correlações entre: A) fluxo de óxido nitroso e temperatura do solo na área de agricultura com plantio direto (B112T1); B) fluxo de óxido nitroso e temperatura do solo na área de agricultura com plantio direto (B129T9); C) fluxo de óxido nitroso e temperatura do solo na área de capoeira; D) fluxo de óxido nitroso e temperatura do solo na área pastagem; E) fluxo de óxido nitroso e WFPS na área de agricultura com plantio direto (B112T1); e F) fluxo de óxido nitroso e WFPS na área de agricultura com plantio direto (B129T9).

A correlação entre a temperatura e o fluxo de óxido nitroso na área de capoeira foi fraca (figura 6C). Dados da literatura sugerem que a conversão de floresta em pastagem pode causar um aumento significativo na emissão de óxido nitroso; no entanto, alguns estudos tem mostrado que o aumento do fluxo desse gás 
em pastagem é transitório (VERCHOT et al., 1999). Em Paragominas (PA), pastagens jovens e antigas e algumas pastagens ativas apresentaram valores mais baixos que a floresta primária (VERCHOT et al., 1999).

Na área de pastagem ocorreu correlação significativa entre a temperatura do solo e o fluxo de óxido nitroso (figura 6D). Assim, os maiores valores de fluxos corresponderam as menores temperaturas. Na área de agricultura B112T1 e B129T1 o fluxo de óxido nitroso e sua relação com a WFPS foi descrita por uma função linear simples e se correlacionaram diretamente (figuras 6E e 6F). Nas demais áreas não houve correlação entre os fluxos e WFPS.

De acordo com o modelo de 'hole-in-the-pipe' (HIP) descrito por Firestone et al. (1989), os fluxos de gases nitrogenados a partir do solo são controlados por dois fatores: pela concentração de nitrogênio que cicla através do sistema e pelo teor de água no solo que rege a difusão de oxigênio e outros gases. As áreas de agricultura (B112T1 e B129T9) onde ocorreu correlação demonstraram que a quantidade de água no solo determina o fluxo de óxido nitroso validando assim o modelo HIP.

De acordo com o modelo de Davidson (1993), valores altos de óxido nitroso são esperados quando a WFPS se encontra na faixa de $50-90 \%$, pois a aeração do solo torna-se limitada e as atividades de desnitrificação tornam-se máxima e o óxido nitroso torna-se o gás mais abundante emitido. Os valores encontrados nas áreas pesquisadas encontram-se entre 40 e $65 \%$.

\section{CONCLUSÕES}

Nesse estudo, não foi identificado diferença nos fluxos de metano quando se compara as áreas de agricultura, capoeira e pastagem. Para o fluxo de óxido nitroso agricultura e pastagem se comportaram de maneira semelhante, porém diferente dos fluxos de capoeira. Na agricultura, com relação ao sistema de cultivo adotado, para os fluxos de metano e óxido nitroso existe diferença significativa entre o plantio direto e o plantio convencional.

A temperatura do solo se correlacionou com o fluxo de metano apenas no transecto de agricultura (B112T1) e com a área de pastagem; o mesmo ocorreu para o óxido nitroso. Com relação aos espaços porosos preenchidos por água, apenas os transectos de agricultura em sistema de plantio direto se correlacionaram com o fluxo de óxido nitroso. As fracas correlações nas áreas estudadas entre os fluxos dos gases em com as variáveis ambientais sugerem que outros fatores estão participando do controle dos fluxos de metano e óxido nitroso. Tendo em vista que ainda pouco se conhece sobre os processos de interação de gases na biosfera-atmosfera, e de como as mudanças de uso e cobertura de solo podem altera-lo faz se necessário à realização de mais estudos voltados à descrição e entendimento dos processos.

\section{REFERÊNCIAS}

CARVALHO, A. M.; BUSTAMANTE, M. M. C.; KOZOVITS, A. R.; MIRANDA, L. N.; VIVALDI, L. J.; SOUSA, D. M.. Emissões de óxidos de nitrogênio associada à aplicação de uréria sob plantio convencional e direto. Pesquisa Agropecuária Brasileira, v.29, n.4, p.679-685, 2006. DOI: http://doi.org/10.1590/S0100-204X2006000400020
DAVIDSON, E. A.. Soil Water content and the ratio of nitrous oxide to nitric oxide emitted from soil. In: OREMLAND, R. S. The Biochemistry of Global Change: Radiace Trace Gases. Washington (DC): ASM, 1993. p.369-386.

DAVIDSON, E. A.; ISHIDA, F. Y.; NEPSTADE, D. C.. Effects of an experimental drought on soil emissions of carbon dioxide, methane, nitrous oxide, and nitric oxide in a 
moist tropical forest. Global Change Biology, v.10, p.718730, 2004. DOI: https://doi.org/10.1111/j.13652486.2004.00762.x

ESCOBAR, L. F.. Emissão de gases de efeito estufa em sistemas de manejo em solo do Planalto Médio do Rio Grande do Sul. Dissertação (Mestrado em Ciência do Solo) Universidade Federal de Santa Maria, Santa Maria, 2007.

FIRESTONE, M. K.; DAVIDSON, E. A.. Microbiological basic of $\mathrm{NO}$ and $\mathrm{N}_{2} \mathrm{O}$ production and consumption in soil. In: ANDREA, M. O.; SHIMEL, D. S.. Exchange of trace gases between terrestrial ecosystems and the atmosphere. New York: John Wiley \& Sons, p.7-21, 1989.

GOMES, J.. Emissão de gases do efeito estufa e mitigação do potencial de aquecimento global por sistemas conservacionistas de manejo do solo. Tese (Doutorado em Ciência do Solo) - Universidade Federal do Rio Grande do Sul, Porto Alegre, 2006.

IBAMA. Instituto Brasileiro do Meio Ambiente e dos Recursos Naturais Renováveis. Floresta Nacional do Tapajós: Plano de Manejo. Belterra: IBAMA, 2004.

INMET. Instituto Nacional de Meteorologia. Normas Climatológicas. Brasília: INMET, 2010.

JANTALIA, C. P.; ZOTARELLI, L.; SANTOS, H. P.; TORRES, E.; URQUIAGA, S.; BODDEY, R. M.; ALVES, B. J. R.. Em busca da mitigação da produção de óxido nitroso em sistemas agrícolas: avaliação de práticas usadas na produção de grãos do sul do País. In: ALVES, B. J. R.; URQUIAGA, S.; AITA, C.; BODDEY, R. M.; JANTALIA, C. P.; CAMARGO, F. A. O.. Manejo de sistemas agrícolas: impacto no sequestro de $C$ e nas emissões de gases de efeito estufa. Porto Alegre: Genesis, 2006. p.81-108.

KELLER, M., MITRE, M. E.. Consumption of atmospheric methane in soils of central Panama effects of agricultural development. Global Biogeochemical Cycles, v.4, p.21-27, 1990. DOI: https://doi.org/10.1029/GB004i001p00021

LAURANCE, W. F.; ALBERNAZ, A. K. M.; FEARNSIDE, P. M.; VASCONCELOS H. L.; FERREIRA, L. V.. Deforestation in Amazonia. Science, v.304, p.1109-1111, 2004. DOI: http://doi.org/10.1126/science.304.5674.1109b

LIU, X. J.; MOSIER, A. R.; HALVORSON, A. D.; ZHANG, F. S.. The impact of nitrogen placement and tillage on $\mathrm{NO}, \mathrm{N}_{2} \mathrm{O}$, $\mathrm{CH}_{4}$ and $\mathrm{CO}_{2}$ fluxes from a clay loam soil. Plant Soil, v.280, p.177-188, 2006. DOI: https://doi.org/10.1007/s11104-005$\underline{2950-8}$
MATSON, P. A.; BILLOW, C.; HALL, S.. Fertilization practices and soil variations control nitrogen oxide emissions from tropical sugar cane. Journal of Geophysical Research, v.101, n.13, p.18533-18545, 1996. DOI:

https://doi.org/10.1029/96JD01536

MORAES, J. L.; CERRI, C. C.; MELILLO, J. M.; KICKLIGHTER, D.; NEILL, C.; SKOLE, D. L.; STUEUDLER, P. A.. Soil carbon stocks of de Brazilian Amazon basin. Soil Science Society of America Journal, v.59, n.1, p.244-247, 1995. DOI: http://doi.org/10.2136/sssaj1995.03615995005900010038x

MOSIER, A. R.; SCHIMEL, D. S.; VALENTINE, D. W.; BRONSON, K.; PARTON, W. J.. Methane and nitrous oxide in native fertilized and cultivated grasslands. Nature, v.350, p.330332, 1991.

MOURA, J. M. S.. Fontes de metano em florestas tropicais da Amazônia: análise da composição isotópica e uso de técnicas indiretas para a determinação de balanços gasosos nesses ecossistemas. Tese (Doutorado em Ciências) Universidade de São Paulo, Piracicaba, 2010.

OSTERMAYER, F.. Estudo das emissões de gases formadores do efeito estufa e balanço resultante da conversão de motores à gasolina de uma frota de veículos leves para gás natural e álcool hidratado. Tese (Doutorado em Engenharia) - Universidade Federal do Rio Grande do Sul, Porto Alegre, 2004.

PAVEI, M. A.. Decomposição de resíduos culturais e emissão de gases do efeito estufa em sistemas de manejo do solo em Ponta Grossa (PR). Dissertação (Mestrado em Ecologia de Agroecossistemas) - Universidade de São Paulo, Piracicaba, 2005.

SAMPAIO, I. C. G.; OLIVEIRA JUNIOR, R. C.; KELLER, M.; PEREIRA, C.; OLIVEIRA, K.. Análise do fluxo de metano na interface solo-atmosfera de uma plantação de arroz, uma plantação de soja e uma floresta tropical, na Amazônia Oriental. Espaço Científico (ULBRA), v.1, p.1-6, 2006.

VERCHOT, L. V.; DAVIDSON, E. A.; CATTÂNIO, J. H.; ACKERMAN, I. L.; ERICKSON, H. E.; KELLER, M.. Land use change and biogeochemical controls of nitrogen emissions from soil in eastern Amazon. Global Biogeochemistry Cycles, v.13, p.31-46, 1999.

ZANATTA, J. A.; BAYER, C.; VIEIRA, F. C. B.; KUHN, N.; MIELNICZUK, J.. Emissões de óxido nitroso em sistemas de manejo de solo no RS. In: REUNIÃO BRASILEIRA DE MANEJO E CONSERVAÇÃO DO SOLO E DA ÁGUA, 17. Anais. Rio de Janeiro: 2008.

A CBPC - Companhia Brasileira de Produção Científica (CNPJ: 11.221.422/0001-03) detém os direitos materiais desta publicação. Os direitos referem-se à publicação do trabalho em qualquer parte do mundo, incluindo os direitos às renovações, expansões e disseminaçães da contribuição, bem como outros direitos subsidiários. Todos os trabalhos publicados eletronicamente poderão posteriormente ser publicados em coletâneas impressas sob coordenação da Sustenere Publishing, da Companhia Brasileira de Produção Científica e seus parceiros autorizados. Os (as) autores (as) preservam os direitos autorais, mas não têm permissão para a publicação da contribuição em outro meio, impresso ou digital, em português ou em tradução. 